\title{
Bezafibrate for the Treatment of Hypertriglyceridemia in HIV1-Infected Patients on Highly Active Antiretroviral Therapy
}

\author{
Juliana Geraix, Micheli Evangelista de Souza \\ Francieli Cristina Delatim and Paulo Câmara Marques Pereira
}

\author{
Tropical Diseases Department, Faculty of Medicine of \\ Botucatu, State University of São Paulo - UNESP; \\ Botucatu, SP, Brazil
}

\begin{abstract}
The use of highly active antiretroviral therapy (HAART) in HIV-infected patients has been associated with the development of risk factors for cardiovascular diseases (CD) including dyslipidemia and insulin resistance, hypertriglyceridemia being the most frequent metabolic disturbance in these patients. Fibrates are indicated when hypertriglyceridemia is accentuated and persists for over six months. We evaluated the efficacy and safety of bezafibrate for the treatment of hypertriglyceridemia in HIV-infected individuals on HAART. All patients received $400 \mathrm{mg} /$ day of bezafibrate and were evaluated three times: Mo (pre-treatment), $M_{1}$ (one month after treatment), and $M_{2}$ (six months after treatment). Fifteen adult individuals, eight males and seven females with mean age $=41.2 \pm 7.97$ years and triglyceride serum levels $\geq 400 \mathrm{mg} / \mathrm{dL}$ were included in the study. Smoking, alcohol ingestion and sedentarism rates were $50 \%, 6.66 \%$ and $60 \%$, respectively. Family history of $\mathrm{CD}$, hypertension and diabetes mellitus was reported in $33.3 \%, 40 \%$ and $46.7 \%$ of the cases, respectively, while dyslipidemia was reported by only $13.3 \%$. More than half of the patients were using a protease inhibitor plus a nucleotide analog transcriptase inhibitor. Eutrophy and tendency toward overweight were observed at all three study time points. There were significant reductions in triglyceride serum levels from Mo to $M_{1}$ and from $M o$ to $M_{2}$. No significant changes were observed in the serum levels of creatine phosphokinase, hepatic enzymes, $\mathrm{CD}_{4}{ }^{+}, \mathrm{CD}_{8}{ }^{+}$and viral load. Therefore, bezafibrate seems to be safe and effective for the reduction of hypertriglyceridemia in HIV-infected patients on HAART. Key Words: HIV, HAART, hypertriglyceridemia, bezafibrate.
\end{abstract}

In 1996, the treatment of AIDS remarkably changed with the large-scale use of a new class of antiretroviral (AR) drugs - protease inhibitors (PI). The discovery of these agents allowed the introduction of highly active antiretroviral therapy (HAART), which led to a dramatic decline in the number of deaths from AIDS [1]. However, at the same time, HIV-infection and the use of antiretroviral therapies were found to be associated with metabolic abnormalities, such as lipodystrophy (fat redistribution), insulin resistance and dyslipidemia [2-7].

In the pre-HAART era, abnormal serum triglyceride (TG) levels in HIV-infection were considered to be a sign of a gloomy prognosis and were associated with weight loss, body mass depletion and low levels of total cholesterol (TC), VLDL, HDL and LDL [8-11]. More recently, hypertriglyceridemia without weight loss and increased TC, VLDL and LDL, or insulin resistance and body fat redistribution have been observed in AIDS patients [12]. A common denominator between the AIDS patients of the past and those of the HAART era is low HDLcholesterol levels [6,9].

Received on 27 January 2006; revised 15 May 2006.

Address for correspondence: Dr. Paulo Câmara Marques Pereira. Faculty of Medicine of Botucatu, State University of São Paulo Unesp, Tropical Diseases Department. Distrito de Rubião Júnior s/ no , cep:18618-000 Botucatu, SP, Brazil. Phone: (14)3811-6212, Fax: (14)3815-9898. E-mail: ppereira@fmb.unesp.br.

The Brazilian Journal of Infectious Diseases 2006;10(3):159-164. (C) 2006 by The Brazilian Journal of Infectious Diseases and Contexto Publishing. All rights reserved.
The pathogenic mechanisms underlying hyperlipidemia in HIV-infection are not clear. Several causes, still requiring scientific corroboration, have been suggested, including elevated circulating levels of cytokines due to chronic viral infection [8], PI direct effects [3,5,12], AR therapy effects that lead to sudden changes in infection severity and immunological status, endocrinological abnormalities [6], and changes in the activity of the complement and autoimmune reactions [6].

The risks due to hypertriglyceridemia in patients not infected with HIV include accelerated atherosclerosis and pancreatitis [13], but its consequences in HIV-infected individuals are unknown. Nevertheless, recently-reported cases of pancreatitis and premature cardiovascular disease associated with AR therapy, are matters of concern $[14,15]$. Gallet et al. [15] reported the development of coronary disease (acute myocardial infarction) in patients on PI with elevated levels of serum TC and TG; three of them required angioplasty. Indeed, acceleration of the atherosclerotic process following HAART has been widely reported [16-23].

Carr et al. [14] observed lipodystrophy and hyperlipidemia in $83 \%$ versus $4 \%$, and $74 \%$ versus $28 \%$ of the patients on PI and those who were not, respectively. In another study, the use of ritonavir-saquinavir was associated with increased levels of insulin, TG and TC, as well as severe lipodystrophy and metabolic abnormalities [9].

The medication indicated for the treatment of dyslipidemia includes statins and fibrates. Fibrates are recommended for the treatment of endogenous hypertriglyceridemia when changes in lifestyle (diet + physical activity) are not enough or hypertriglyceridemia is too high ( $>400 \mathrm{mg} / \mathrm{dL})$ [24-26]. 
Henry et al. [27] reported that dyslipoproteinemia may be improved, but not normalized, with the use of gemfibrozil or atorvastatin, or a combination of both, with no adverse effect within six months following treatment. Special care should be taken when using fibrates or statins in HIV-positive patients on protease inhibitors because of their metabolic interaction with the hepatic cytochrome P450 [27]. HIV-positive patients may already have abnormalities in hepatic enzymes and could receive other drugs with potential for undesirable interactions, including reduction in viral suppression.

Fibrates are hypolipemic drugs whose mechanisms of action are complex and still unclear. They are known to reduce the flow of fatty acids to the liver, decrease VLDL hepatic synthesis, stimulate lipoprotein-lipase activity and increase the biliary excretion of hepatic cholesterol [28]. Several classes of fibrates, including bezafibrate, have been used to reduce TG serum levels. Ericsson et al. [29] observed a decrease of $21 \%$ in triglyceride levels among cardiopathic patients receiving bezafibrate. The management and treatment of HIVinfected individuals with dyslipidemia aims at preventing pancreatitis in cases of severe hypertriglyceridemia and atherosclerotic diseases in hypercholesterolemia and mixed dyslipidemias.

We evaluated the efficacy and safety of bezafibrate (Cedur ${ }^{\circledR}$ Retard) for the treatment of hypertriglyceridemia in HIV-1 patients on HAART.

\section{Material and Methods}

Study subjects. This study included 15 adult patients, both males and females, with a diagnosis of HIV established by the ELISA method and hypertriglyceridemia serum levels $>400 \mathrm{mg} /$ dL. All the patients attended the Outpatient Clinic of Nutrition in Tropical Diseases of the Faculty of Medicine of Botucatu, State University of São Paulo - UNESP, Brazil and were on the same HAART regimen for at least three months. Exclusion criteria included age $<18$ years, pregnancy, hypothyroidism, diabetes mellitus, nephritic syndrome, chronic renal failure, chronic cholestatic hepatopathy and Cushing syndrome, use of diuretic drugs, b-blockers, corticosteroids, contraceptives, estrogens, progestagens or cyclosporines. The study protocol was approved by the institutional Ethics Board, and informed written consent was obtained from all study subjects.

Intervention All subjects received $400 \mathrm{mg}$ of oral bezafibrate (Cedurâ Retard) once a day, after breakfast, for six months.

Data collected. All subjects were evaluated at three different moments: baseline (Mo), 30 days $\left(\mathrm{M}_{1}\right)$ and six months $\left(\mathrm{M}_{2}\right)$ following intervention. The categories of information collected were epidemiological, clinical-nutritional, biochemical and immunological features. At baseline, data collected included age, gender and ethnics. The anthropometric data collected were weight, height and abdominal circumference. In addition, the body mass index was calculated [BMI = weight $(\mathrm{kg}) /$ height $^{2}(\mathrm{~m})$ ] for the establishment of a nutritional diagnosis based on the values proposed by the World Health Organization (WHO) [30]. The abdominal circumference values were analyzed according to the values associated with high risk for cardiovascular diseases [24]. The follow-up laboratory tests performed included total cholesterol, HDL-cholesterol, LDL-cholesterol, triglyceride, glucose, creatine phosphokinase (CPK), alanine aminotransferase (ALT), aspartate aminotransferase (AST), gamma glutamil transpeptidase (GGT), $\mathrm{CD}_{4}^{+}, \mathrm{CD}_{8}^{+}$and viral load. Sample collections were made after 12-hour fasting, 24-h restriction of intense physical activity and 72-h alcohol abstention. Biochemical and immunological tests were conducted at the Faculty of Medicine of Botucatu, State University of São Paulo Clinical Laboratory and Blood Center, respectively.

Statistical analysis. The data were analyzed at the Research Support Facility of the Faculty of Medicine of Botucatu, State University of São Paulo - UNESP, using calculations of mean values, standard deviation and the non-parametric KruskalWallis test for comparison at each study moment. Statistical significance was set at $\mathrm{p}<0.05$.

\section{Results}

Among the 15 study subjects, eightwere males and seven were females, and 14 were white and one was black. Mean age was $41.2 \pm 7.97$ years. Smoking and alcohol ingestion rates were $50 \%$ and $6.66 \%$, respectively. At baseline, $60 \%$ of the subjects were sedentary. In relation to family history, $33.3 \%$ of the individuals reported cardiac diseases, $40 \%$ hypertension, $46.7 \%$ diabetes mellitus and $13.3 \%$ dyslipidemia.

AR therapy included protease inhibitor plus nucleotide analog transcriptase inhibitor (PI+NATI) in 54\% of the cases, nucleotide analog transcriptase inhibitor plus nucleotide reverse transcriptase inhibitor (NATI+NRTI) in 33\% and other AR combinations in 13\%. All subjects received the same regimen for at least three months. Mean treatment duration was $21.9 \pm 22.0$ months.

The nutritional diagnosis that prevailed at the three study moments was eutrophy with tendency towards overweight (Figure 1). Of the 15 individuals, five (two males and three females) showed abdominal circumference values associated with high risk for cardiovascular diseases.

There was a significant reduction in triglyceride serum levels (Figure 2). The serum levels of CPK as well as hepatic enzymes remained unchanged, except for GGT, which significantly decreased within the intervals (Figure 3). Eight subjects were excluded from the study; seven of them dropped out and one showed a significant increase in serum creatine phosphokinase.

No significant changes were observed in the levels of $\mathrm{CD}_{4}^{+}, \mathrm{CD}_{8}^{+}$and viral load after adding bezafibrate to the antiretroviral regimen (Figure 4). 
Figure 1. Distribution of subjects at the three study time points, according to the nutritional diagnosis based on the calculation of body mass index (BMI)

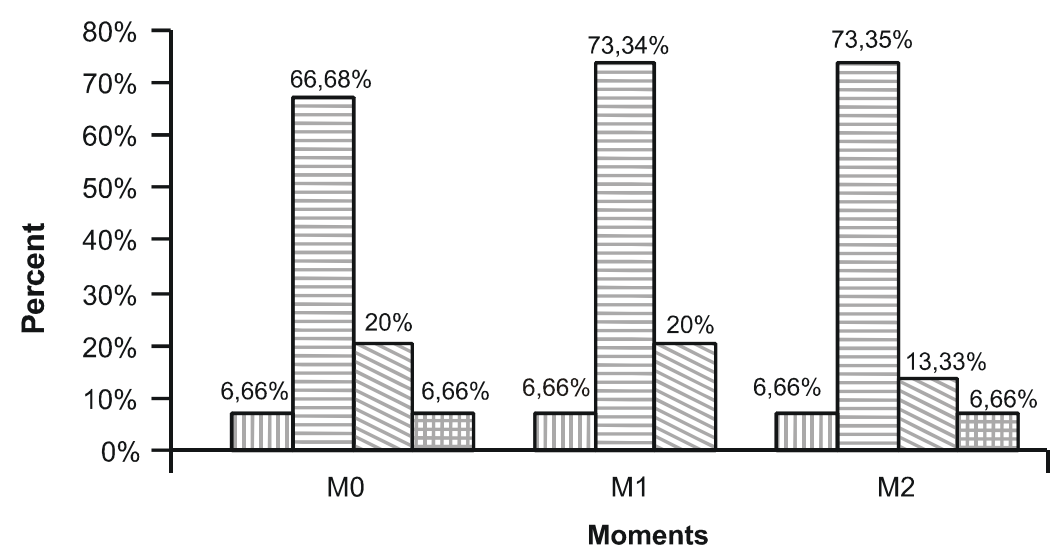

II Level II mal nutrition

Eutrophy

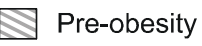

姍 Level I obesity

$\mathrm{Mo}=$ before bezafibrate

$M_{1}=1$ month after bezafibrate

$M_{2}=6$ months after bezafibrate

Figure 2. Mean serum lipid pattern and glucose pattern at the three study time points

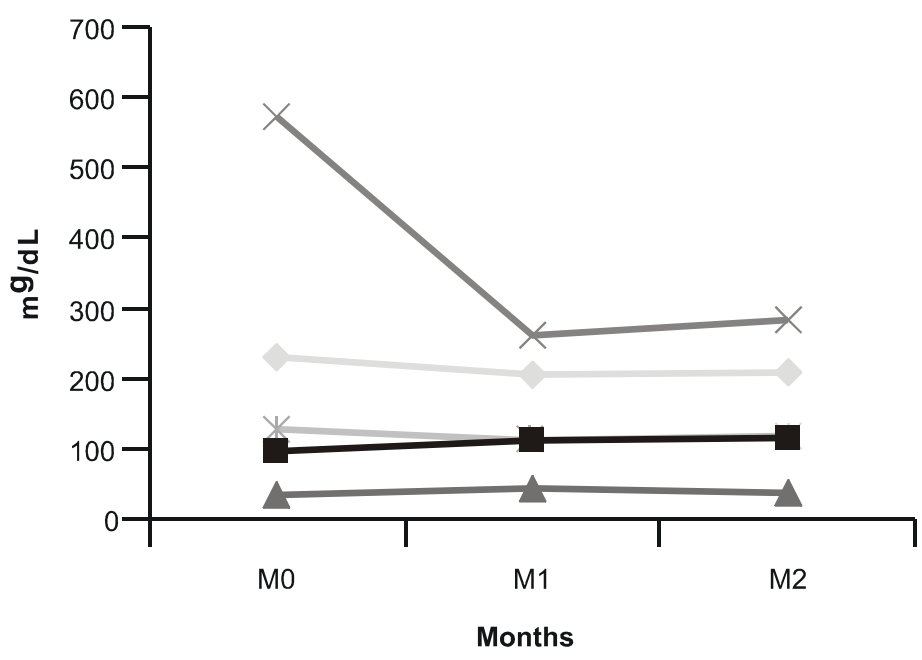

Figure 3. Mean serum biochemical values at the three study time points

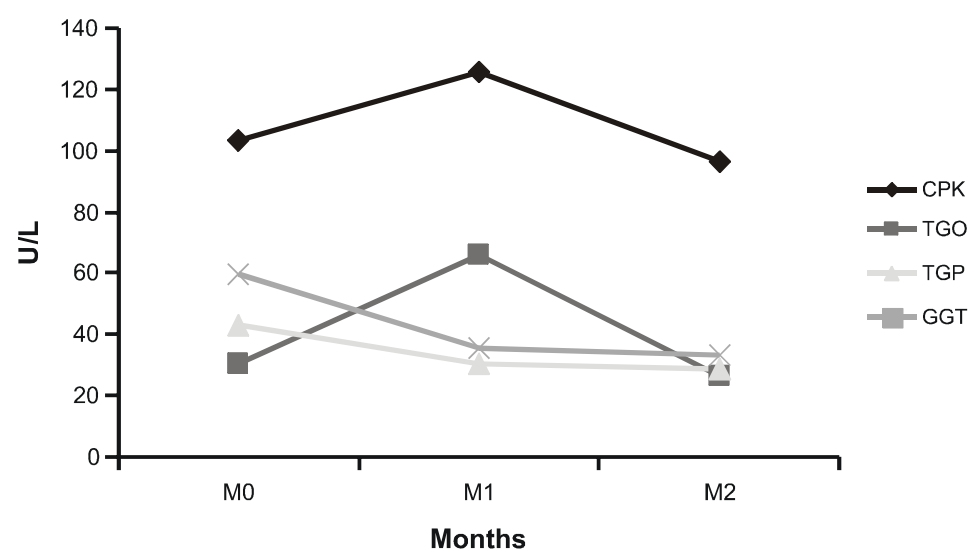

www.bjid.com.br

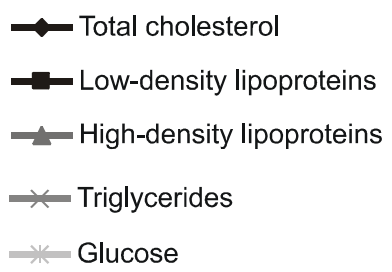

Mo: mean serum lipid pattern and glucose pattern $(\mathrm{mg} / \mathrm{dL})$ before bezafibrate

$M_{1}$ : mean serum lipid pattern and glucose pattern (mg/dL) 1 month after bezafibrate

$M_{2}$ : mean serum lipid pattern and glucose pattern (mg/dL) 6 months after bezafibrate

$$
\begin{aligned}
\chi^{2}=26,0563-p<0,05-M_{0} & >M_{1} \\
M_{0} & >M_{2}
\end{aligned}
$$

Mo: Mean (U/L) serum pattern of CPK and hepatic enzymes before bezafibrate

$\mathrm{M}_{1}$ : Mean (U/L) serum pattern of CPK and hepatic enzymes one month after bezafibrate

$\mathrm{M}_{2}$ : Mean (U/L) serum pattern of CPK and hepatic enzymes six months after bezafibrate

$$
\chi^{2}=6,2520-p<0,05-M_{0}>M_{1}
$$


Figure 4. Mean $\mathrm{CD}^{+}$and $\mathrm{CD}^{+}$serum values and percent of undetectable viral load at the three study time points

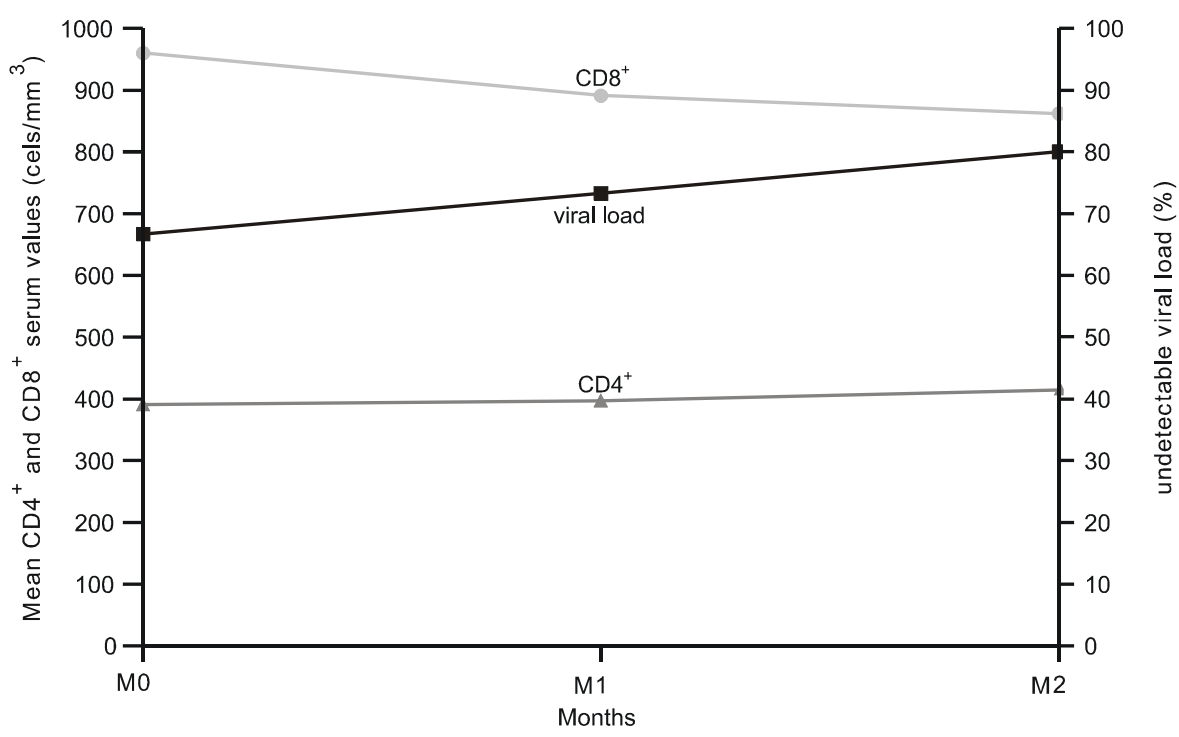

Mo: Mean (cels $\left./ \mathrm{mm}^{3}\right) \mathrm{CD}_{4}^{+}$and $\mathrm{CD}_{8}^{+}$ serum values and percent undetectable viral load before bezafibrate

$\mathrm{M}_{1}$ : Mean $\left(\right.$ cels $\left./ \mathrm{mm}^{3}\right) \mathrm{CD}_{4}^{+}$and $\mathrm{CD}_{8}^{+}$ serum values and percent undetectable viral load one month after bezafibrate $\mathrm{M}_{2}$ : Mean (cels $\left./ \mathrm{mm}^{3}\right) \mathrm{CD}_{4}^{+}$and $\mathrm{CD}_{8}^{+}$ serum values and percent undetectable viral load six months after bezafibrate

\section{Discussion}

Hyperlipidemia may occur in up to $60 \%-80 \%$ of HIV-infected individuals receiving HAART, including hypertriglyceridemia in most cases $(40 \%-100 \%$ of the individuals treated), hypercholesterolemia in 10\%-50\% and hyperglycemia and hyperinsulinemia, which are less frequent (5\%-3-\%) [31-35].

Some investigators have reported that high TG levels in HIV1-infected individuals receiving HAART can also increase the relative risk for cardiovascular diseases (CD) $[36,37]$. Achutt [38] reported that one third of the death causes documented and identified in Brazil, about 260,555, were related to $\mathrm{CD}$, with dyslipidemia being a predisposing factor that can also lead to pancreatitis [39].

In our study, the mean age was $41.2 \pm 7.97$ years, within the distribution of notified AIDS cases in Brazil, where approximately $75 \%$ of the cases are aged $25-49$ years [40]. Our data on gender are similar to those reported in the literature, which reveal an increase in the proportion of infected females [41]. Baseline rates of smoking and sedentarism, which are important isolated risk factors for $\mathrm{CD}[28,42]$, were $50 \%$ and $60 \%$, respectively.

Another important aspect that is often reported is the fact that dyslipidemia may be related to the antiretroviral regimen used. Behrens et al. [43] and others [14,44] evaluated the lipid pattern of HIV-1 infected individuals treated with and without PI; they found hyperlipidemia and/or hypertriglyceridemia in $57 \%-74 \%$ of the individuals on PI. In our study, over $50 \%$ of the patients were also on an antiretroviral regimen that included at least one PI.

The nutritional diagnosis showed a predomination of eutrophy with tendency toward overweight and obesity that, when associated with sedentarism, are known to increase the risk of developing dyslipidemia and hence CD [42]. Moreover, $1 /$ 3 of the subjects had abdominal circumference values that are associated with high risk for CD. Dolan et al. [37] also reported a significant increase in $\mathrm{CD}$ rate associated with abdominal fat accumulation in women. Thus, the association of smoking, sedentarism, overweight and excessive body fat in HIV-infected individuals, as well as the use of HAART, are likely to contribute to increases in metabolic abnormalities and their consequences.

The mechanisms underlying these metabolic abnormalities are still not completely understood. The pathways postulated to explain HAART-associated lipid alterations include induction of peripheral insulin resistance, inhibition of lipoprotein-lipase caused by tumor necrosis factor-alpha, the suppression of HIV replication or changes in endocrine homeostasis [45].

A hypolipemic diet and physical exercises may improve dyslipidemia, but pharmacological treatment is necessary when dyslipidemia is excessive and persists for six months or more. Moreover, choosing the appropriate hypolipemic drug is difficult because of expected drug-drug interactions, increased risk of toxicity or intolerance and poor patient compliance to multipharmacological regimens [46-49].

Fibrates are a class of hypolipemic agents that are effective for the treatment of hypertriglyceridemia and mixed dyslipidemia because of their increased activity in the hepatic synthesis of triglycerides and cholesterol, lipoprotein-lipase and acetil-CoA-carboxylase, as well as their favorable effect on the inhibition of peripheral lipolysis and glycemic control [45]. These medications are also metabolized by the hepatic cytochrome P450 and may provoke an adverse interaction with AR agents [27].

In our study, a single daily dose of bezafibrate $(400 \mathrm{mg})$ proved effective in reducing serum triglyceride levels. Significant reductions in triglyceride levels were observed after one and six months. This reduction in TG serum levels contributed towards reducing the risk of patients developing 
$\mathrm{CD}$, even though normal levels were not achieved. These findings are in agreement with literature reports; Archana et al. [46] reported a significant decline in serum TG in 55 patients who received $160 \mathrm{mg} /$ day of fenofibrate for six months, though they also did not normalize. Palacios et al. [50], in a prospective study of 20 patients on HAART for at least 12 weeks, with TG serum levels $>400 \mathrm{mg} / \mathrm{dL}$, receiving a single dose of $200 \mathrm{mg}$ of fenofibrate for 24 weeks, reported significantly reduced but not normal levels. Calza et al. [45] evaluated the role of several hypolipemic drugs for the treatment of dyslipidemia in HIVinfected patients receiving HAART and reported that single doses of bezafibrate $(400 \mathrm{mg})$ and fenofibrate $(200 \mathrm{mg})$ contributed to significantly reduce TG serum levels.

Studies on the use of fibrates, especially bezafibrate, to reduce hypertriglyceridemia in HIV-infected individuals on HAART are scarce. Hepatic alterations have been reported in HIV-infected patients on HAART. Fibrates, which are metabolized by the hepatic enzymes of cytochrome P450 might interact with AR drugs and cause toxicity, leading to increased serum levels of hepatic transaminase and creatine phosphokinase [51,52]. However, we did not observe these adverse effects. There was no increase in ALT, AST, GGT and $\mathrm{CPK}$, and there were no significant changes in the values of $\mathrm{CD}_{4}^{+}, \mathrm{CD}_{8}^{+}$and $\mathrm{CV}$. In most hypertriglycemic patients, viral infection is under control and their immunological response to AR therapy is good [6,9], revealing that these drugs are effective, without undesirable side effects.

Therefore, a single $400 \mathrm{mg}$ dose of bezafibrate to treat hypertriglyceridemia in individuals receiving HAART seems to be effective and safe and might contribute towards decreasing risk factors for developing $\mathrm{CD}$ and pancreatitis. Further studies are required to achieve a better understanding of these metabolic alterations, with longer follow-ups, and investigation of the pharmacological interactions with AR agents and side effects, aiming at better management of dyslipidemia in HIV-infected patients on HAART.

\section{Acknowledgements}

We thank the Roche Laboratory for supplying bezafibrate (Cedur ${ }^{\circledR}$ Retard) during this study, and the Research Support Facility of the Faculty of Medicine of Botucatu, State University of São Paulo - UNESP for the statistical analysis used in this research.

\section{References}

1. Ferrini M.T., Pasternak J., Waitzberg D.L. Síndrome da Imunodeficiência Adiquirida (AIDS). In: Waitzberg D.L. Nutrição oral, enteral e parenteral na prática clínica. 3. ed. São Paulo: Atheneu, 2000.

2. Patella Jr F.J., Delaney K.M., Moorman A.C., et al. Declining morbidity and mortality among patients with advanced human immunodeficiency virus infection. N Engl J Med 1998;338(13):853-60.
3. Martinez R., Casamitjana I., Gatell J.M. Protease inhibitor associated hyperinsulinaemia. AIDS 1998;12(15):2077-9.

4. Sullivan A.K., Nelson M.R. Marked hyperlipidaemia on ritonavir therapy. AIDS 1997;11(7); 938-9.

5. Viraben R., Christian A. Indinavir-Associated Lipodystrophy. AIDS 1998; 12:F13 -39.

6. Carr A., Samaras K., Chisholm D.J., Cooper D.A. Pathogenesis of HIV-1 - protease inhibitor - associated peripheral lipodystrophy, hyperlipidaemia and insulin resistance. Lancet 1998 b;20; 351(9119):1881-3.

7. Carr A., Samaras K., Burton S., Law M., Freund J., Chisholm D.J. et al. A syndrome of peripheral lipodistrophy, hyperlipidaemia and insulin resistence in patients receiving HIV protease inhibitors. AIDS 1998a;12:F51-8.

8. Grunfeld C., Kotler D.P., Shigenaga J.K., et al. Circulating interferon-a levels and hypertriglyderidemia in the Acquired Immunodeficiency Syndrome. Am J Med 1991;90:154-62.

9. Caar A., Samaras K., Burton S., et al. A syndrome of peripheral lipodystrophy, hyperlipidaemia and insulin resistence in patients HIV receiving protease inhibitors. AIDS 1998a;12(7):F51-58.

10. Grunfeld C., Kotler D.P., Hamadeh R., et al. Hypertriglyceridemia in the Acquired Immunodeficiency Syndrome. Am J Med 1989;86:27-31.

11. Kotler D.P. Update on lipid abnormalities and cardiovascular complications in HIV infection. In: Program and abstracts: XXXVIII Satellite Symposium ICAAC (San Diego), San Diego, 1998.

12. Kotler D.P., Tierney A.R., Wang J., Pierson Jr R.N. Magnitude of body- cell-mass depletion and the timing of death from wasting in aids. Am J Clin Nutr 1989;50:444-7.

13. Frick M.H., Elo O., Haapa K., et al. Helsinki heart study: primary prevention trial with gemfibrozil in middle-age men with dyslipidemia. Safety of treatment, changes in risk factors, and incidence of coronary artery disease. N Engl J Med 1987;317(20):1237-45.

14. Carr A., Samaras K., Thorisdottir A., et al. Diagnosis, prediction, and natural course of HIV-1 protease-inhibitor-associated lipodystrophy, hyperlipidaemia, and diabetes mellitus: a cohort study. Lancet 1999;353:2093-9.

15. Gallet B., Pulik M., Genet P., et al. Vascular complications associated with use of HIV protease inhibitors. Lancet 1998;351:1958-60.

16. Henry K., Melore H., Huebsch J., et al. Severe premature coronary artery disease with protease inhibitor [letter]. Lancet 1998;351(9112):1328.

17. Juette A., Salzeberg B., Franzen C., et al. Increase morbidity from severe coronary heart disease in HIV-patients receiving protease inhibitor. In: Program and abstracts: VI Conference on Retroviruses and Opportunistic Infections (Chicago), Chicago, 1999.

18. Dong B.J., Gruta C.I., Legg J.J. Diabetes and use of protease inhibitor. In: Program and abstracts: XII World AIDS Conference (Geneva), Geneva, 1998.

19. Mishriki Y.Y. Baffling case of bulging belly. Protease punch. Postgrad Med 1998;104(3):45-6.

20. Madge S., Kinloch-De Loes S., Tyrer M., Johnson M.A. Lipodystrophy syndrome (LS) in patients on reverse transcriptase inhibitors. In: Program and abstracts: VI Conference on Retroviruses and Opportunistic Infections (Chicago), Chicago, 1999. 
21. Gervasoni C., Ridolfo A.L., Trifiro G., et al. Redistribution of body fat in HIV-infected women undergoing combined antiretroviral therapy. AIDS 1999;13(4):465-71.

22. Kotler D.P, Ellen S., Engelson E.D. Summary report - Third International Conference on Nutrition in HIV Infection MEDSCAP HIV/AIDS 5 (3), 1999.

23. Galli M., Ridolfo A.L., Gervasoni C. Cardivascular disease risk factors in HIV-infected patients in the HAART Era. Ann N Y Acad Sci 2001;946:200-13.

24. III Diretrizes Brasileiras Sobre Dislipidemias e Diretriz de Prevenção da Aterosclerose do Departamento de Atersclerose da Sociedade Brasileira de Cardiologia. Arq Bras Cardiol 2001;77(S III).

25. Adult AIDS Clinical Trial Group Cardiovascular Disease Focus Group. Preliminary guidelines for the evaluation and management of dyslipidemia in adults infected with human immunodeficiency virus and receiving antiretroviral therapy: recommendations of adult aids clinical trial group cardiovascular disease focus group. Clin Infect Dis 2000;31:1216-24.

26. National Cholesterol Education Program. Summary of the third report of the National Cholesterol Education Program (NCEP) Expert Panel on the Detection, Evaluation and Treatment of High Blood Cholesterol in Adults (Adult Treatment Panel III). JAMA 2001;10:299-313.

27. Henry K., Huebesch J., Hermundson J., Simpson J. Atorvastatin and gemfibrozil for protease-inhibitor-related lipid abnormalities. Lancet 1998;352:1031-2.

28. Santos D.S. Abordagem prática do manuseio das dislipidemias associadas à infecção pelo HIV e seu tratamento. BJID 2004;8:22-36.

29. Ericsson C.G., Hamsten A., Nilsson J., Grip L., Svane B., de Faire U. Angiographic assessment of effects of bezafibrate on progression of coronary artery disease in young male postinfarction patients. Lancet 1996;347:849-53.

30. World Health Organization. Obesity: preventing and managing the global epidemic of obesity. In: Report of the WHO consultation of obesity. Geneva, 3-5 june, 1997.

31. Calza L., Manfredi R., Chiodo F. Statins and fibrates for the treatment of hyperlipidaemia in HIV-infected patients receiving HAART. AIDS 2003;14:851-9.

32. Stein J.H. Managing cardiovascular risk in patients with HIV infection. J Acquir Immune Defic Syndr 2005;38:115-23.

33. Sanjay N.P., Dravid A., Naik E., et al. Lipodystrophy and dyslipidemia among patients taking first-line, World Health Organization-recommended highly active therapy regimens in Western India. J Acquir Immune Defic Syndr 2005;39:199-202.

34. Kamin D.S., Grinspoon S.K. Cardiovascular disease in HIVpositive patients. AIDS 2005;19:641-52.

35. Dolan S.E., Hadigan C., Killilea K.M., et al. Increased cardiovascular disease risk indices in HIV-infected women. J Acquir Immune Defic Syndr 2005;39:44-54.

36. Achutt A. Epidemiologia das doenças cardiovasculares (DCV): Dados do Brasil. Curso de Reciclagem em Cardiologia da Sociedade de Cardiologia do RS/SBC, 2003. www.cardiol.com.br
37. Szwarcwald C.L., Bastos F.I., Andrade C.L.T., Castilho E.A. Aids: o mapa ecológico do Brasil 1982-1994. In: A epidemia da aids no Brasil: situação e tendências. Brasília: Ministério da Saúde. Coordenação Nacional de DST e Aids. Ministério da Saúde Brasília 1997;p.27-44.

38. Boletim epidemiológico. AIDS ANO XVII n ${ }^{\circ} 01.01$ a 52 Semanas epidemiológicas janeiro a dezembro de 2003. Available from: http:// www. Aids.gov.br/final/dados/bol_aids 1.htm

39. Wilcox J.K., Catignani G.L., Lazarus S. Tomatoes and cardiovascular health. Crit Rev Food Sci Nutr 2003;43(1):1-18.

40. Behrens G., Dejam A., Schmidt H., et al. Impaired glucose tolerance, beta cell function and lipid metabolism in HIV patients under treatment with protease inhibitors. AIDS 1999; 13:F63 - 70.

41. Schmidt H.H., Behrens G., Genschel J., et al. Lipid evaluation in HIV-1-positive patients treated with protease inhibitors. Antivir Ther 1999;4:163-70.

42. Carr A., Cooper D. Adverse effects of antiretroviral therapy. Lancet 2000;356:1423-30.

43. Penzak S.R., Chuck S.K. Hyperlipidemia associated with HIV protease inhibitor use: pathophysiology, prevalence, risk factors and treatment. Scand J Infect Dis 2000;32:111-23.

44. Brewer H.B. Hypertriglyceridemia: changes in the plasma lioproteins associated with an increased risk of cardiovascular disease. Am J Cardiol 1999;83:3F-12.

45. Calza L., Manfredi R., Chiodo F. Statins and fibrates for the treatment of hyperlipidaemia in HIV-infected patients receiving HAART. AIDS 2003;17:851-9.

46. Manfredi R. Management of dyslipidemia in patients with HIV disease. Clin Microbiol Infect 2000;6:579-84.

47. Saint-Marc T., Partisani M., Poizot-Martin I., et al. Fat distribution evaluated by computed tomography and metabolic abnormalities in patients undergoing antiretroviral therapy: preliminary results of the LIPOCO study. AIDS 2000; 14:37-49.

48. Moyle G.J., Baldwin C. Lipid elevations during non-nucleoside RTI (NNRTI) therapy: a cross-sectional analysis. Antivir Ther 1999;4(Suppl 2):54.

49. Sullivan A.K., Feher M.D., Nelson M.R., Gazzard B.G. Marked hypertriglyceridemia associated with ritonavir therapy. AIDS 1998; $12: 1393-4$.

50. Palacios R., Santos J., González M., Ruiz J. Letters to the editor: Efficacy and safety of fenofibrate for the treatment of hypertriglyceridemia associated with antiretroviral therapy. JAIDS 2002;31:251-2.

51. Dresser G.K., Spence J.D., Bailey D.G. Pharmacokineticpharmacodynamic consequences and clinic relevance of cytochrome p450 3A4 inhibition. Clin Pharmacokinet 2000;38:41-57.

52. Mastroianni C.M., d'Ettorre G., Forcina G., et al. Rhabdomyolisis after cerivatatin-gemfibrozil therapy in an HIV-infected patient with protease inhibitor-related hyperlipidaemia. AIDS 2001;15:820-1. 